\title{
A Time like no Other: Covid-19 in Women's Voices, N. Hadebe, D. Gennrich, S. Rakoczy, and N. Tom
}

The Circle of Concerned African Women Theologians. 2021. Johannesburg, South Africa. pp. 227. ISBN 978-0-620-92420-7

\section{Reviewed by Graham A Duncan}

https://orcid.org/0000-0002-2583-1914

Department of Systematic and Historical Theology, Faculty of Theology and Religion University of Pretoria

graham.duncan@up.ac.za

This book is a timely contribution to the discussion of the impact of the Covid-19 pandemic, with a specific focus on South Africa. It is a project of the Circle of Concerned African Women Theologians, South Africa. Although its primary focus is the pandemic, it links this to the ongoing issue of gender based violence (GBV) where women carry a double burden of anxiety. It highlights, in particular, problematic issues associated with grieving for those who have died.

The book is structured in six parts: tribute and trauma; lament; ministry challenges; trials and faith; multiple experiences; and hope. The contributions consist of theological reflections, personal narratives, worship resources, poems and letters. All, in their own way, are moving and heartrending. One focus that is particularly relevant, is lament as a source of hope in the quest for gender justice and human dignity. Palm helpfully explores a feminist theology of hope by adopting Keshgegian's five contours of hopeseeing time differently; accepting finitude; challenging transcendence; an ethnic risk; and reconceptualising transformation.

A number of issues arise in this volume. First, the Covid-19 pandemic and GBV touch all aspects of life and disrupt natural forms of fellowship and communication, where relationships become remotely controlled. Second, the contributions recorded here present authentic voices marked by a singular integrity. Third, the contributions demonstrate the enormous courage women have garnered to expose themselves in all their vulnerability, pain and angst. Fourth, this book may give courage to those who suffer isolation with negative feelings due to their sense of alienation and have yet to find their voice. Fifth, we can see the sharp contrast with the moral cowardice of those

\section{UNISA $\cong$}




\section{Duncan}

who bully and abuse women and children in the dark recesses of the home, which should be a place of safety during the pandemic.

This book of trauma stories, all of which are primary sources, is a must for all, but particularly religious leaders whose members are those whose stories are recounted here and who, most likely, suffer in silence out of fear for their lives and those of their family members. The Circle of Concerned African Women Theologians, South Africa, are to be congratulated for taking this initiative and for maintaining their role in engaging with contemporary issues theologically. 